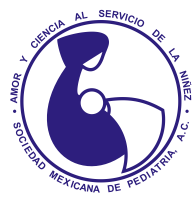

\title{
La pantalla en negro de las clases en línea
}

\author{
The black screen of online education
}

\author{
José Luis Pinacho-Velázquez* \\ * Hospital Ángeles Lindavista, Sociedad Mexicana de Pediatría. Ciudad de México.
}

A los profesores que estamos utilizando la educación en línea de manera habitual, tanto para alumnos de pregrado de medicina como para residentes, nos está sucediendo que los estudiantes apagan sus cámaras y el audio durante las clases. Este fenómeno se ha denominado: "la pantalla en negro". Investigaciones en curso reportan que es muy frecuente que existan pantallas en negro en las que, en muchas ocasiones, pareciera que el profesor predica en el desierto.

Debo reconocer que en mis 20 años de práctica docente, en la Facultad de Medicina de la Universidad Nacional Autónoma de México y en otras instituciones superiores, no había vivido esta experiencia. La pandemia por COVID-19 ha impactado enormemente las prácticas de docencia universitaria. Si bien se había avanzado en educación en línea, la mayoría de las clases en línea que se han implementado en los meses de pandemia en México corresponden a una respuesta de emergencia a la crisis sanitaria.

La educación a distancia descansa en un diseño y planificación cuidadosa con vasta evidencia, y se rige por indicaciones instruccionales definidas. Esta forma de educación se utiliza en universidades reconocidas de todo el mundo, y ha demostrado importantes avances en la última década. Sin embargo, en comparación con la educación presencial, la educación a distancia podría considerarse de menor calidad, si no se realiza de acuerdo con las bases fundamentales; por ejemplo, una buena planificación puede requerir de seis a nueve meses. Las clases que hoy se organizan no reúnen estas características. La emergencia sanitaria incluyó el confinamiento, lo que ha llevado a las instituciones de educación superior a implementar cursos en línea sin mayor preparación, diseño, capacitación o evidencia.

Otro punto para destacar es que la educación a distancia incluye una forma diferente de relación profesorestudiante, así como entre estudiante-estudiante. Por ejemplo, los estudiantes de cualquier curso, si acaso, sólo conocen el nombre de sus compañeros, pero no otras características que se logran habitualmente en la convivencia presencial. Además, cuando sólo se tienen actividades en línea, los alumnos pueden perder el sentido de identidad de la institución educativa a la que pertenecen, ya que no están familiarizados con las instalaciones de su escuela o facultad y, por supuesto, ni con sus directivos.

Si bien es posible que las "pantallas en negro" sea un problema que se puede explicar por dificultades en la conexión, por temor al consumo de datos móviles, por sentirse invadidos en su intimidad (cuando no se dispone de un espacio específico para conectarse en casa), o bien, porque desnudan la falta de recursos económicos, es también una oportunidad para reflexionar y modificar nuestra propia conducta, es decir, convertirnos en docentes de esta época. De ahí la invitación a flexibilizar, priorizar, ser creativos e inclusivos para evitar que se afecten las competencias que se desean desarrollar en los estudiantes.

Correspondencia: José Luis Pinacho-Velázquez, E-mail: joselpinacho@hotmail.com

Citar como: Pinacho-Velázquez JL. La pantalla en negro de las clases en línea. Rev Mex Pediatr. 2021; 88(5): 177-178. https://dx.doi. org/10.35366/103895 
Las cámaras apagadas generan falta de comunicación. Dejemos de ver solamente los nombres de los alumnos, y tratemos de interactuar con ellos. El lenguaje corporal es muy importante para conocer cómo se está llevando el aprendizaje. Por esta razón, es relevante que podamos incentivar a nuestros alum- nos a que abran sus cámaras, y lograr un contacto más cercano.

En un futuro deseo que, al cruzarme en los pasillos de escuelas de medicina y hospitales, pueda identificar a mis alumnos por sus rostros y que ellos me reconozcan. Por eso, hoy no quiero ver más pantallas en negro. 